\title{
An Analysis of Use of conditional Sentences by Arab Students of English
}

\author{
Sadam Haza' Al Rdaat \\ Coventry University, United Kingdom \\ E-mail: saddamhazzaa@gmail.com \\ Sheena Gardner \\ Coventry University, UK \\ E-mail: ab1248@ coventry.ac.uk
}

\author{
Doi:10.7575/aiac.alls.v.8n.2p.1 \\ URL: http://dx.doi.org/10.7575/aiac.alls.v.8n.2p.1
}

Received: 04/01/2017

Accepted: 17/02/2017

\begin{abstract}
Conditional sentences are made of two clauses namely "if-clause" and "main clause". Conditionals have been noted by scholars and grammarians as a difficult area of English for both teachers and learners. The two clauses of conditional sentences and their form, tense and meaning could be considered the main difficulty of conditional sentences. In addition, some of non-native speakers do not have sufficient knowledge of the differences between conditional sentences in the two languages and they tried to solve their problems in their second language by using their native language. The aim of this study was to analyse the use of conditional sentences by Arab students of English in semantic and syntactic situations. For the purpose of this study, 20 Arab students took part in the questionnaire, they were all studying different subjects and degrees (bachelor, master and $\mathrm{PhD}$ ) at Coventry University. The results showed that the use of type three conditionals and modality can be classified as the most difficult issues that students struggle to understand and use.
\end{abstract}

Keywords: conditional sentences, protasis and apodosis, mood, real and unreal clauses, tense-time

\section{Introduction}

In the last few decades, scholars and researchers have broadly debated conditionality. They have essentially concentrated on philosophy and then progressively moved onto linguistics. According to Traugott et al (1986), linguistic studies suppose that every language has a theory of forming conditional sentences. These conditionals are expressed in various ways which differ from language to language (Sultan 2011). Many scholars have discussed what conditional sentences mean, their structures, the main aims for enhancing them and how they can be acquired. Further research about conditional sentences may find some method by which to acquire them easily and simply.

\subsection{Background to the Topic}

This section gives a background of English and Arabic conditional sentences. English conditionals are considered complex, both cognitively and linguistically, and they can have a lot of different meanings that are conveyed using different forms. In addition, semantic and syntactic difficulties are considered the main obstacles for NNSs trying to acquire conditional sentences (Celce-Murcia and Larsen-Freedman 1999). Learners of English as a foreign language (EFL) encounter a big obstacle in acquiring conditionals. According to Norris (2003) and Ramires (2005), the difficulty of conditionals goes back to the reliance of one situation on the fulfilment of another. There are different possible meanings of conditional sentences, such as cognitive reasoning, counterfactual, possible and impossible, real and unreal, and hypothetical (ibid). More specifically, forms, meanings and time-tense relationships cause the major difficulties in conditional sentences (Nekoueizadeh and Bahrani 2013). On the other hand, Arabic conditionals are simple and easy to produce, while they become more difficult when they shift to conveying complex meanings.

Conditional clauses and if-clauses are other terms related to conditional sentences. Conditional sentences in both languages (English and Arabic) contain two clauses: an if-clause (subordinate clause or protasis) that consists of a condition and a main clause (result clause or apodosis) that consists of a proposition (Teschner and Evans 2007; Fintel 2009). The essential point of conditional sentences is that the action in the main clause can happen if the specific situation in the if-clause is fulfilled. English conditionals predominantly convey the logical meaning "if $p$, then $q$ " and implement different expressions, for instance, reasoning and imagining correlations (Traugottet al, 1986). Some grammarians and scholars say there are three main types of conditional: (1) future, (2) present and (3) past; however, other grammarians and scholars say there are four types: zero, future, present and past conditionals. One the other hand, there are only two types of Arabic conditional. The first type is the real conditional, which includes fulfilled conditions and uses two particles ("in" and "ithaa"), while the second is the unreal conditional, which includes the unfulfillable conditional and the use of the particle "lau". 


\section{Literature Review}

\subsection{Conditional Sentences in English}

Conditional sentences are used to indicate the cause and effect or the temporal sequence of two events. The main structure of conditionals contains "an antecedent clause" and "consequent clause" or" protasis" and "apodosis" (Traugott et al 1986; Yule 1998; Zhang 2005; Polanska 2006). The antecedent is defined as a subordinate clause referring to a supposition situation, while the consequent consists of a proposition situation that occurs if the antecedent is realised (Elliot 1981; Dancygier 1998; Young 1989). Conditionals predominantly convey the logical sense "if situation $P$, then situation $Q$ " and carry out different functions, for instance imaging, inference, habitual, factual and reasoning (Geis and Zwicky 1971; Traugott et al, 1986). In English conditionals, the future is usually expressed by the present tense, the unreal present or future are expressed by the past tense and impossible events which did not occur in the past are expressed by the past perfect (Comrie 1986).

\subsubsection{Previous Studies}

Conditional sentences have been extensively noted as a difficult area of English to acquire and few researches have been able to state for certain why conditional sentences make L2 learners uncomfortable. Additionally, they have been analysed from various angles. For example, Cuvalay (1996) and Dik (1990) analyse them in linguistics from a functional grammar viewpoint. In addition, semantics and pragmatics have been analysed by Beck (1997) and Fintel (1997). In the early grammar method, conditional sentences were analysed within the mood term simultaneously with the imperative and indicative under the subjunctive (Sweet 1991). Conditionals are occasionally examined within the area of tenses or under modals. They are not simple to acquire for students, even though "if" is the most overt conditional marker. There are many researchers who have noted this obstacle in second language acquisition. Moreover, Bloom et al (1980) and O'Grady (1997) investigated the acquisition of the "if-conditional" and indicated the slow process of acquiring the "if-clause". Conditionals are thought to be difficult for non-native speakers because the acquisition of them is actually complicated. The significant issues pertaining to conditional sentences (Covitt 1976) involve four angles: (1) forms; (2) meanings; (3) time-tense linkages and (4) simplified interpretations. Although the challenges and problems of conditionals come from the interactions of meaning (temporal and hypothetical situations) and form (verb form), as has been argued, it is very important to discuss their relationships and how they consistently come in conditional sentences.

It is a known fact that the past tense is not a real past tense in counterfactual conditionals, therefore the tense cannot simply be a basic component related to the past. Tense and verb forms have a relationship in conditionals, which is referred to as "back-shifting", and it makes the case more difficult. It is defined as "the use of morphologically past tense with present (or future) time reference and pluperfect with past time reference" (Comrie 1986:94). Comrie also claimed that "back-shifting" is especially used for unreal conditions.

\subsubsection{Construction of English Conditional}

According to Celce-Murcia and Larsen-Freeman (1999), some grammarians believe that there are three types of conditional sentence (i.e. future, present and past). However, other grammarians (Yule 1998; Cowan 2008; Zhang 2005; Liu 2011; Wu 2012) have said there are four types of conditional, namely zero, future, present and past conditionals. It is worth noting that the understanding of conditionals can fall into one of two wide categories, namely factual (real) and unreal, which depend on the verb form in the antecedent part. In the factual (predictive) structure, the antecedent part refers to a condition, the reality of which is unconfirmed, and the verb in the consequent clause can be in three tenses, namely past, present and future (Palmer 2001). In addition, factual and real conditionals include four features: generic, habitual, inference and future conditionals (Yule 1998; Cowan 2008; Wu 2012). In unreal conditionals, the antecedent refers to a condition that is known to be untrue or unlikely. Unreal conditionals are also divided into two major types, namely counterfactual and hypothetical (Yule 1998; Cowan 2008; Wu 2012) (see appendix 1). The result of hypothetical (as opposed to factual) construction consists of conditional verb forms that contain "would" (or "might", "could", "should") and the base form of the verb or the previous verb with "have" and the past-participle.

According to Guilani et al (1999) and Celce-Murcia and Larsen-Freeman (1999), conditionals can refer to three kinds of semantic relationship, namely factual, future or predictive and imaginative conditionals, while according to Yule (1998) and $\mathrm{Wu}$ (2012), conditionals consist of four types of semantic relationship: factual, predictive, hypothetical, and counterfactual. Figure 1 shows the distribution of conditional sentence relations: 


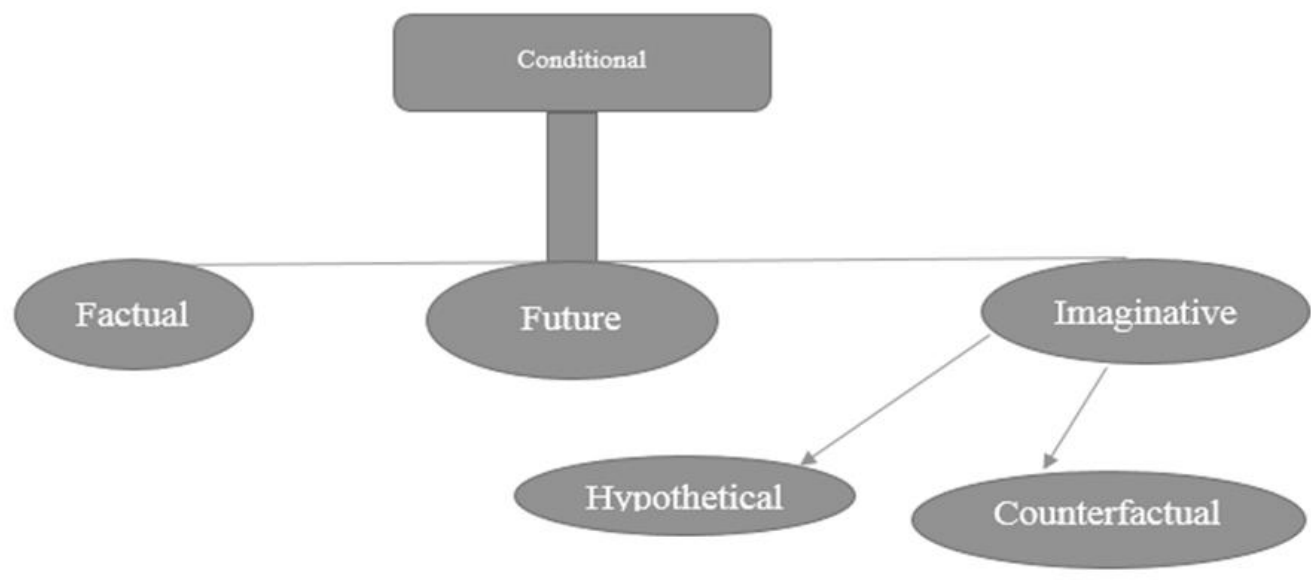

Figure 1. The distribution of conditional sentence relations

Table 1, below, shows the probabilities of conditional sentences as proposed by $\mathrm{Wu}$ (2012).

Table 1. The probabilities of conditional sentences as proposed by $\mathrm{Wu}(2012)$

\begin{tabular}{|l|c|}
\hline \multicolumn{2}{|c|}{ Probability of conditional sentences } \\
\hline Factual & $100 \%$ \\
\hline Predictive & $50 \%$ \\
\hline Hypothetical & $10 \%$ \\
\hline Counterfactual & $0 \%$ \\
\hline
\end{tabular}

\subsubsection{Conditional sentences types}

As it has been mentioned before, conditional sentences are made of two major types namely real and unreal conditionals:

\section{A. Real Conditionals}

1. Zero Conditional: This type of conditional talks about general truths, scientific facts or something that is constantly true in specific conditions (Eastwood 1994 and Cowan 2008). The main structure for this type is (If + present tense, present tense or If + past tense, past tense).

2. First Conditional: This conditional is used to express possibilities, either in the present or in the future. In this conditional, there is the very likely and real possibility that the condition or the specific situation will happen in the future. The modals "can", "may" and "should" can be used in this type (Declerck and Reed 2001).The main structure for this type is (if + present simple, will + base form).

\section{B. Unreal Conditionals}

1. Second conditional: This conditional is called "non-past" or "present" (Katu'za 1986). It talks about unreal events in the present or in the future. The simple past tense is used in this case to express the present or future situation. The auxiliary verb "were" is always used in this condition with all persons in the "if-clause" and it is a form of wish or desire. The structure for this type is (If + past tense, would +base form).

2. Third conditional: This conditional talks about unreal events in the past. This means that it is used to talk about events that did not occur in the past. The structure for this kind is (If + past perfect, would have + past participle).

\subsection{Conditional Sentences in Arabic}

These conditional sentences are made up of two parts (clauses). The first part is called the "if-conditional" clause (jumlat el-shart) and is used to introduce and specify the condition, and the second part is called the "result-clause" (jawab el-shart), and is used to provide the result of the condition (Dancygier 1998; Ryiding 2005; Khalil 2010; Kumakiri 2013). In Arabic, the "if-clause" usually precedes the "result clause" and the main verb is usually followed by the marker. 
In Arabic, a past tense verb is often used in the protasis (if-clause) while the jussive mood (al amr) (orders and commands) can be used in the protasis of the present tense verb. The apodosis often uses the same tense that is used in the previous clause, but it can be expressed by a different tense. When the tense differs between clauses, the apodosis is normally preceded by the marker " $f a$ " as in this example: /?dara?etahom, fa-salemalehom / "if you see them, then say $h i$ to them" (Ryiding 2005; Taha 1995; Mace 1998). The verb "to be" (in Arabic "kāna") is used if the prodasis clause does not have a verb (Khalil 2010).

The essential particles in Arabic which are roughly equivalent to "if" in English are as follows: "in"/?n/, "ithaa"/?ðə/ and "lau"/ləo/. These markers specify the kind of condition expressed. The particles "in" and "ithaa" are used in fulfilled conditions, whereas the particle "lau" is used in an unfulfilled condition. The particles "in" and "ithaa" are similar and exchangeable. The essential variation is that the particle "in" expresses more certainty, while the particle "lau" refers to hypothetical statements, and if the two clauses are in the past tense, the result of the protasis clause typically begins with the particle "la" (Abboud and McCarus 1983).

\subsection{The Main Similarities and Differences between English and Arabic Conditional Sentences}

There are major similarities between English and Arabic conditionals. For example, both of them have three main types, many particles and two clauses (the if-condition and the result condition). In addition, in both languages, conditionals use two clauses to perform the conditional situation. Despite these similarities, there are also many differences between the two languages. For instance, in Arabic, the kind of condition is determined by the use of various conditional markers, while in English, the sequence of the verb forms determines the kind of condition. In addition, in English conditionals, the if-condition clause may follow or precede the result clause, whilst in Arabic ones, the result clause usually follows the if-condition clause. Additionally, the three English conditional sentence types have three verbs (should, were and had respectively) that can be replaced by the particle "if", but Arabic does not have these verbs, though command verbs can be used in Arabic. In English, the auxiliary verb "were" is usually used in type two with all persons; however, in Arabic, this rule is not used (Wickens 1980; Celce-Murcia and Larsen-Freeman 1999; Ryiding 2005). According to Wickens (1980), Ryding (2005), Ruth and Byrne (2007) and Jasim (2015), the tense that indicates an impossible situation in English conditionals is the past perfective, while verbs in Arabic conditionals are in the perfect tense.

\subsection{Previous Studies about English Conditional Sentences Carried Out by Arab Researchers}

According to this study, which is looking at how Arab students use and deal with English conditional sentences, many studies have been done before about this topic. Based on these studies, Saeed (2004) researched the acquisition of English conditionals by Arab students have been meagre. In addition, he found that the problems that Arab students encounter the most relate to the meaning of conditionals and trying to translate from their native language. In another study, Kharma and Hajjaj (1989) provided a wide analysis of the errors and mistakes that Arab students of English make in conditional sentences. These errors and mistakes are representative of the meaning and form of conditional sentences. They also added that Arab students often cannot understand the meaning when speech acts are used in conditionals. Furthermore, they indicated that the difference between two clauses may create a big difficulty (Kharma and Hajjaj 1997). In addition, they assert that the harmony between the two verbs in the two clauses is a source of difficulties for students and their teachers. Furthermore, there is a related study by Fareh (2006), she found that the main problem that the students faced indicates their inability to connect form to function in conditionals; this shows that function recognition may be considered the greatest challenge for Arab students. The results also show that the relationship between the two clauses is integrated, which forms another hard challenge for students. Additionally, meaning recognition was ranked second in terms of difficulty when compared with function. Accordingly, the study also found that the students' recognition of meaning was lower than their performance in recognising form. This means that Arab students generally face difficulties in the recognition of conditionals.

\subsection{The Gap in the Literature}

As has been presented above, previous studies have shown some of the problems and challenges that Arab students encounter when using conditional sentences. Previous research has not been inclusive and hence this study is seeking to focus on more difficulties and challenges that Arab students face when using conditional sentences. For instance, most of Arab students encounter some problems with the semantic and syntactic issues of conditionals, which is considered a big problem for native English speakers as well. Furthermore, the relationships between time tenses and matching between the verb forms in the two clauses have been classified as the most challenging aspects for Arab students. Additionally, the verb forms in both conditional clauses rely on each other, which is classified as another big difficulty. In addition, most Arab students do not know where the modal verbs are usually used in conditional sentences. They think that using the modal verbs "could", "should", "might" and "ought to" is incorrect as an alternative to the modal verbs "will" and "would". The other problem that Arab students usually face relates to the form "if $P$, then $Q$ "; most of them use the coordination conjunction (then) at the beginning of conditional sentences. Furthermore, Arab students cannot usually distinguish between type two and type three conditionals. They consider type three the greatest obstacle in conditional sentences. In type three, most Arab students use the present perfect tense instead of the past perfect in the if-condition clause. In addition, they cannot comprehend how the verb "had" and its past participle "had" come together (for example: "If I had had a car, I would have visited you"); this problem is faced by most Arab students. 


\section{Methodology}

The researcher collected quantitative and qualitative primary data for this research through a self-administered questionnaire, which was considered suitable for gathering data for these methods. The quantitative data were gathered by two phases namely checking and rewriting the sentences, whereas the qualitative data were collected by explanations phase. The questionnaire was selected to find out the main issues that Arab students encounter when using conditional sentences. The questionnaire contained 15 conditional sentences including each of the three main types of conditional (see appendix2). It focused on the major corrections that Arab students usually face. 20 Arab students, studying different subjects at different levels (bachelor, master and $\mathrm{PhD}$ ) at Coventry University took part in the questionnaire (11 male and nine female). The questionnaire was carried out in the library over four days. The researcher got the students' email address from the head of the Arabic society at the university. All the students received an email about the procedure, time and place of the questionnaire by email. All the participants had already attained 6.5 or more in IELTS tests; this meant that they were able to deal with the questionnaire (test). The participants carried out the test voluntarily to measure their skills. In addition, the participants were from Arab countries (some of them from Gulf countries, while others were from Iraq, Syria, Jordan and Palestine), were studying in different faculties including engineering, business and humanities, and their ages ranged from 20 to 32.The data was analysed quantitatively and qualitatively. In addition, thematic analysis was used to analyse the qualitative data and to code them for ease of discussion.

\subsection{Questionnaire Structure}

The questionnaire consisted of 15 conditional sentences and the participants answered them in less than 30 minutes. The conditional sentences were designed carefully and deliberately related to the research questions and the purpose of the research. The questions mainly focused on conditional sentence types one, two and three. 12 out of 15 sentences were originally incorrect, while the rest were correct (5, 8 and 14). Each sentence contained a specific structure of two parts so as to obtain qualitative and quantitative data.

In data analysis part, statistical analysis was carried out on the quantitative data in two phases, namely checking and rewriting the incorrect sentences, while the respondent's explanations were the third phase (i.e. where the conditional sentences were incorrect, the participants explained and justified why they were incorrect). In addition, the first two sentences were not analysed, because they did not provide authentic or credible answers, as some students who had never filled in a questionnaire before used them as practice.

\section{Result and Discussion}

This chapter shows the findings and discussions of the research and consists of four sections. The first three sections of the chapter provides the findings and the discussions of the quantitative and qualitative data (i.e. from the checking, rewriting and explanations phases) of each type of conditional sentences, while the four section provides some results about transfer from L1 to L2.

\subsection{Conditional Sentences Types}

\section{Type one}

This type was included in three of the conditional sentences that were used in the questionnaire:

6. If Sadi will go home, he will see his aunt.

12. Then they will see you if you come here again.

14. If we need some queries, we should ask the receptionist.

Table 2. The number and percentage of the students who marked the type one conditionals as correct/incorrect

\begin{tabular}{lccc}
\hline \multicolumn{1}{r}{ sentence } & Correct & Incorrect & No Answer \\
\hline 6. & $7(35 \%)$ & $13(65 \%)$ & 0 \\
\hline 12. & $17(85 \%)$ & $2(10 \%)$ & $1(5 \%)$ \\
\hline 14. & $9(45 \%)$ & $9(45 \%)$ & $2(10 \%)$
\end{tabular}

Table 2 illustrates the results for three sentences containing type one conditionals. For sentence 6 , almost half of the participants had difficulty judging the use of the modal verb in the if-clause. They also encountered difficulties when they attempted to rewrite it again as type one or two. It could be said that this sentence was complicated for the participants, because they thought that the use of "will" in the if-clause was misleading (Al-Khawalda 2013).

For sentence $12,85 \%$ of the participants could not judge the conditional correctly. They faced a serious problem here, because it is possible that they considered this sentence correct because they used their native language to judge it, which is inconsistent with the relevant literature (Traugott et al. 1986), in which conditionals predominantly conduct the logical sense "if situation $P$, then situation $Q$ ". Unfortunately, the participants' choice was wrong because the adverb "then" does not have a connective function and there was no preceding sentence; this means that it is not appropriate to use it at the beginning of conditionals. In the next sentence (14), most of the participants encountered a considerable 
level of difficulty in judging this sentence correctly, although it was originally correct. Most of them marked it as incorrect and rewrote it (incorrectly). According to Fareh (2006), Arab students cannot deal with the variations of conditional sentences properly.

The overall percentages of correct scores for the type one conditionals were $40 \%$ for correct marking and $62.5 \%$ for correct rewriting. This indicates that, in the checking phase, $60 \%$ of the participants encountered an obvious level of difficulty in selecting the correct choice and $37.5 \%$ of the participants did not have sufficient ability to rewrite the incorrect conditionals properly. The biggest difficulty may lie in the fact that the simple present and modal verbs are usually used in Arabic conditionals in these particular cases; this could be why the participants faced some problems.

In the explanation phase, conditional sentences type one includes three issues. Two of them were mentioned in correct explanations about incorrect conditional sentences 6 and 12, i.e. the use of modal verbs in if-clauses and the use of "then" placed at the beginning of conditionals. These sentences did not correspond with the main structure for type one conditionals, and these two issues were explained by $36 \%$ of the participants. This means that most of the participants did not give valid explanations or have the knowledge to explain why they marked the sentences as incorrect. On the other hand, the third issue was present in sentence 14, and involved incorrect explanations about the original correctness of the sentence. The issue was the use of modal verbs other than "will" in the main clause. This sentence was consistent with the grammar rules of conditionals, but some participants marked it as incorrect. The issue was explained by $33 \%$ of the participants. This means that most of the participants who marked as correct were able to give valid explanations about this type of sentence.

\section{Type two}

This type was included in five of the conditional sentences that were used in the questionnaire:

3. I would have passed if the exam wasn't difficult.

4. If I was a millionaire, I would buy a yacht.

5. If you had a car, you would go to the party.

11. She will go to London if she had a car.

15. You won't be so tired if you took a nap.

Table 3. The number and percentage of the students who marked the type two conditionals as correct/incorrect

\begin{tabular}{|c|c|c|c|}
\hline sentence & Correct & Incorrect & No answer \\
\hline 3. & $11(55 \%)$ & $8(40 \%)$ & $1(5 \%)$ \\
\hline 4. & $12(60 \%)$ & $8(40 \%)$ & 0 \\
\hline 5. & $11(55 \%)$ & $8(40 \%)$ & $1(5 \%)$ \\
\hline 11. & $2(10 \%)$ & $17(85 \%)$ & $1(5 \%)$ \\
\hline 15. & $11(55 \%)$ & $8(40 \%)$ & $1(5 \%)$ \\
\hline
\end{tabular}

Table 3 demonstrates the results for five sentences of type two and shows that that almost all the participants had the ability to decide whether the five conditionals of type two were correct or not. To go into more detail,the findings regarding type two conditionals clearly show that most Arab students have problems identifying errors in the surface forms of this type of sentence and they encounter serious problems particularly with time-tense and verb forms.

Sentence 3 was rewritten in different ways, these sentences were rewritten as types two and three. The eight participants who marked it as incorrect faced difficulty in the two clauses because of the use of "would have + PP" in the main clause and the simple past tense in the if-clause. In the next Sentence 4 created more difficulty for the participants. They used "would have + PP" in the main clause and the past tense in the if-clause. The participants mismatched the verb forms in the two clauses of the conditionals; this is consistent for Arab learners according to previous studies (Fareh 2006).In this sentence specifically, the participants focused on the "subject verb agreement", which means that they did not pay attention to the main structure or the use of "were" in with all persons in type two conditionals.For sentence 5, although this sentence was correct originally, half of the participants marked it as incorrect. The participants who thought it was incorrect rewrote it in two different ways, these sentences were rewritten as type three. The other correction involved the use of the verb "have" in the if-clause and "would + base form" in the main clause. This refers to the mismatching between the verb forms in the two clauses, which is considered the greatest difficulty that some Arab students face (Kharma and Hajjaj 1989).

For sentence 11, 17participants rewrote it with three different corrections. These corrections included transformations into types one and two and the students used the structures of these types very well. In addition, this sentence was one of the easiest for the participants and all the answers for this sentence refer suggest that most of the participants are familiar with this type of conditional. For the last sentence, 8participants rewrote it in two different ways, using both type one and type two. The two corrections were correct, which means that most of the participants could not distinguish or deal with the modality in types one and two and thought that the modal verb "won' $t$ " can be used with 
type two conditionals, which is wrong. This assumption could be attributed to the inherent semantic difficulty of English modal verbs.

Overall for the five conditionals, $52 \%$ were correctly marked and 53\% were rewritten correctly. This indicates that, during the checking phase, $48 \%$ of the participants encountered obvious difficulties with selecting the correct answer and $47 \%$ of the participants were unable to rewrite the incorrect conditionals properly. These percentages show that most of the participants could not deal with in-depth conditional sentences, which could be ascribed to the fact that students are not typically taught the variants of conditionals.

In the explanation phase, type two contained five issues; four of them were mentioned in correct explanations about incorrect conditionals, which included sentences $3,4,11$ and 15 . These issues were mixing the structures of type three and type two in the two clauses, the use of the auxiliary verb "was" with people in type two, mixing the structures of type one and type two together in the two clauses and the use of the contraction of "will" and "not". The four sentences were inconsistent with the main structure of type two conditionals, which use the simple past in the if-clause to express unreal conditions and "would + base form". The use of the auxiliary "were" may be considered a big difficulty that faced the participants. The issues were explained by $46 \%$ of the participants. This means that $54 \%$ of the participants were not able to give good explanations as to why they marked the sentences as incorrect. This could be ascribed to the fact that Arab students know the grammar rules for this type of conditional but cannot deal with them properly.

Meanwhile, the fifth issue was in sentence five, and was mentioned in some incorrect explanations about the sentence which was originally correct. The issue was "how the participants deal with type two". The sentence was consistent with the main structure for type two, but half of the participants marked it as incorrect. Justifications of this issue were attempted by $50 \%$ of the participants, although naturally all the explanations were incorrect; this means that these participants do not know the rules for this type of conditional and cannot provide good explanations.

\section{Type Three}

This type of conditional was used in the questionnaire in the following conditional sentences:

7. If they have worked more, their job would have been developed.

8. If you had had his contact number, you would have called him anytime.

9. If you had had the book, you would had studied at home.

10. If you would have studied harder, your English would have gotten better.

13. If I had knew earlier, I would have done it.

Table 4. The number and percentage of students who marked the type three conditionals as correct/incorrect

\begin{tabular}{|c|c|c|c|}
\hline Sentence & Correct & Incorrect & No answer \\
\hline 7. & $12(60 \%)$ & $8(40 \%)$ & 0 \\
\hline 8. & $6(30 \%)$ & $14(70 \%)$ & 0 \\
\hline 9. & $5(25 \%)$ & $15(75 \%)$ & 0 \\
\hline 10. & $12(60 \%)$ & $7(35 \%)$ & $1(5 \%)$ \\
\hline 13. & $7(35 \%)$ & $11(55 \%)$ & $2(10 \%)$ \\
\hline
\end{tabular}

Table 4 illustrates the results for the five sentences of type three and shows that almost all the participants were able to decide whether the five type three conditionals were correct or not. In detail, the results for type three conditionals obviously show that most Arab students have problems identifying errors in the surface form of this type of sentence. This type of conditional (type three) was considered the most difficult type that the participants faced in the questionnaire. This assumption is consistent with Fareh (2006), who says that the major problem that Arab students face is the mismatch between the verb forms in the two clauses of a conditional. This means that Arab students typically encounter difficulties in judging the grammaticality of conditionals, which could be attributed to the fact that they learn too much grammar and do not practice it; most of them know the rules but they cannot use them in discourse or writing. The other cause which could be inferred is that Arab students may try to understand the meanings of conditionals by translating them into their native language. In addition, the Arabic language does not have the past perfect tense, which may account for most of the difficulty that Arab students face in type three.

Sentence 7 was difficult for the participants. 12 participants rewrote it in different ways; for example, one of them used the simple past tense in the if-clause and "would have $+P P$ " in the main clause. The result shows that $60 \%$ of the participants found it difficult to decide if it was correct or not, and half of the participants who marked it as incorrect could not rewrite it properly as was required. This means that the greatest difficulty that was revealed was when facing the mismatch between time and tense and the use of the present perfect instead of the past perfect.For sentence 8 that was seriously complicated for the participants. Although this sentence was originally correct semantically and syntactically, three-quarters of the participants marked it as incorrect. Those participants rewrote it in three different ways; for example, four of them changed the tense in the if-clause to the present perfect.This means that the majority of 
the participants could not understand the meaning or the form of conditional sentences of type three and they did not comprehend the use of the auxiliary "had" and its past-participle "had" in the if-clause.

For sentence 9, 15 participants rewrote it in three different ways, as stated in the results chapter. Eight of them used the simple past in the if-clause and two of them used the present perfect in the if-clause, while five of them rewrote it as "if you had had the book, you would have studied at home", which is the correct answer. This means that most of the participants could not deal with the form of the type three conditional either semantically or syntactically, nor with the use of modal verbs in the main clauses of this type. This is consistent with previous studies that observed the same problems in high percentages of Arab students (Al-Khawalda2013). In addition, Arabic does not use the past perfect at all; instead it uses the perfect tense (past), and the students' inability to relate verb forms to their suitable times could be considered one of the possible issues. In sentence 10, a few participants rewrote it, making two different corrections. These corrections used types two and three. In general, the participants' responses in the checking and rewriting phases suggest that they were facing big difficulties. In the next sentence 13, the 11participants who marked it as incorrect rewrote it in two different ways. Three of them deleted the auxiliary "had" from the if-clause to put it in the past tense. However, another eight participants rewrote it as "if I had known earlier, I would have done it" which is the correct answer and it includes an unreal situation and the formal structure for type three conditional sentences. This sentence showed the difficulty of using the auxiliary verb "had + past tense". This problem is faced by both NSs and NNSs. According to Al-Khawalda and Al-Oliemat, Arab students encounter many difficulties when handling tenses, in particular in English conditionals.

The overall percentages for the five type three conditionals were $47 \%$ for marking them correctly and $36 \%$ for rewriting them correctly. This tells us that during the checking phase, $43 \%$ of the participants encountered clear obstacles judging the correctness of this type of conditional and $64 \%$ of them had difficulty rewriting incorrect ones properly. These percentages show that Arab students face big difficulties with type three conditionals. These difficulties could be attributed to the fact that "past time" is expressed by the past perfect. The results revealed that the students do not have much knowledge, especially of type three conditionals, and that they need more practice rather than just to know the rules.

In the explanation phase, this type includes five issues, four of which were included in the students' correct explanations about incorrect conditionals in sentences 7, 9, 10 and 13. These issues were: the use of the present perfect instead of the past perfect in type three, the use of the auxiliary "had" after the modal "would", the use of the structure of the main clause in the if-clause and the use of a past tense verb (knew) after the auxiliary verb "had". The issues were explained by $43 \%$ of the participants; this shows that most of the participants were unable to explain why they marked these sentences as incorrect. which could be attributed to three interpretations: either they could understand the meaning of the conditionals or attempted to understand it by using their native language, they did not have enough knowledge, particularly regarding type three conditionals, or Arab teachers do not focus on teaching type three, perhaps supposing that this type is not frequently used in discourse.

In contrast, the fifth issue was in sentence 8 , and was mentioned in incorrect explanations about the originally correct sentence. The issue was related to the use of the auxiliary "had" with its past participle (past perfect). This sentence was consistent with the main structure for type two, but half of the participants marked it incorrect. This issue was used as an explanation by $41 \%$ of the participants, meaning the participants did not completely understand this type.

The results revealed that there is a pattern of three big problems that almost all the participants faced in the three types of conditional: the use of "then" at the beginning of conditionals of type one, the use of the present perfect in the ifclauses of both types two and three, and the use of the auxiliary "had + PP (had)" in type three. These problems show students' inability to connect forms with functions in conditionals. The findings show that the students do not have sufficient knowledge of the differences between conditional sentences in Arabic and English and they tried to solve problems and overcome challenges in their second language by using their native language.

\section{Does transfer from L1 to L2 inhabit students' ability to handle "if" clauses in English?}

The purpose of this question is to find evidence about the influence of L1 on L2 when students deal with "if" clauses. This influence may be positive or negative. It is positive when L1 helps learners acquire L2, but negative when L1 weakens their ability to understand L2. Furthermore, few studies have been done researching the immediate grammatical transfer of subjects between Arabic and English, which may be considered the main issue that Arab learners face (Al-Khawalda and Al-Oliemat 2013). In addition, Laresen-Freeman (1975) associated the grammatical errors of L2 with the grammar of L1 learners.

20 Arab students took part in the questionnaire. The results showed that some of them encountered issues when handling "if "clauses, therefore they applied their knowledge and familiarity of L1 to check the conditional sentences in English. This means that the learners applied their knowledge from L1 to provide them with an understanding of conditional sentences in English. Some of the Arab students found the conditional sentences complicated and complex to check. This could be ascribed to the different forms conditionals take in Arabic and English. The Arabic language particularly uses the simple present in conditional sentences, with the jussive mood (Khalil 2010). In Arabic, particles determine the conditional type, while in English the verb forms determine the conditional type. The most serious difficulty that Arab students face is that English type three conditionals use the past perfect to express counterfactual events, while in Arabic, conditionals use the perfect tense to express counterfactual events. In general, Arab learners 
encounter a lot of obstacles when using English tenses (ibid). These issues are particularly clear in conditional sentences when there is a mismatch between times, tenses and verb forms.

\section{Conclusion}

The aim of the study was to investigate whether Arab students are able to judge the grammaticality of conditional sentences and give valid explanations as to why some of the conditional sentences in the questionnaire were incorrect. Unfortunately, the study showed that almost half of the students were unable to judge the grammaticality of conditionals correctly (i.e. which sentences were correct and which were not), despite the fact that most of the participants in the research had studied in an English education environment in their countries and are currently studying in the UK. The overall percentage of the participants whose answers were correct (i.e. who chose the correct options) was $47 \%$. This means that more than half of the participants face serious difficulty in judging the grammaticality of conditionals. In addition, the total percentage of participants who gave explanations for the conditionals was $42 \%$; this suggests that most of the participants encounter real challenges with conditionals. One might wonder why the percentage of participants who selected the correct answers regarding the three types was lower than the percentage of participants who explained why some conditionals were incorrect, since the judgment of grammaticality is generally easier than explaining their meanings and functions.

\subsection{Limitations}

This research does have some limitations. Firstly, there were only 20 students taking part, which means that the results cannot show all the difficulties that Arab students face. Secondly, the study focused on the three main types of conditional sentence, but there are also many inversions and variations of conditional sentences, as well as the zero type. The issues related to conditional sentences could be better researched with NSs and NNSs to compare findings. Interviewing the participants and asking them what causes lie behind some of the difficulties which they face would be useful. The researcher analysed the data and all the data was inserted into a program to be classified manually. In this case, it would be arrived to find out more worthy results to enable the researcher to find a comprehensive treatment of conditional sentences subject.

\subsection{Further Research}

This research is about the broad subject of conditional sentences. The results could be considered as evidence of how conditional sentences are understood and practiced by Arab students. Researching these subjects: "a contrastive study of conditional sentences between Arabic and English languages"; "an analysis of the use of conditional sentences by Arab and English students" and "an analysis of the use of conditional sentences by Arab students of English in academic writing" could offer worthy results. In addition, the use of the important results of the current research in wider research could solve some of the difficulties that Arab students face.

\section{References}

Abdollahi-Guilani, M, Yasin, M. and Tan, H, 2012. "A Comparative analysis of conditional clauses in english and persian: text analysis". 3L; Language, Linguistics and Literature, The Southeast Asian Journal of English Language Studies, 18(2), pp.83-93.

Beck, S. (1997) “On the Semantics of Comparative Conditionals”. Linguistics and Philosophy, 20, 229-271.

Bloom, L. Lahey, M. Hood, L. Lifer, K. and Fiess, K. (1980) "Complex sentences: Acquisition of syntactic connectives and the meaning relations they encode". Journal of Child Language, 7, 235-261.

Celce-Murcia, M., \& Larsen-Freeman, D. (1999) The grammar book: An ESL/EFL teacher's course. New York: Heinle, Cengage learning.

Comrie, B. (1986) “Conditionals: A typology”. In E. C. Traugott, A., Meulen, J. S. Reilly and C. A. Ferguson (Eds.), on conditionals, (p 94). Cambridge: Cambridge University. P. 94

Covitt, R. (1976) "Some problematic grammar areas for ESL teachers". Unpublished doctoral thesis in TESOL, UCLA.

Cowan, R. (2008) The Teacher's Grammar of English with Answers: A Course Book and Reference Guide. Cambridge University Press.

Cuvalay, M. (1996) “A Classification of Conditional Satellites”. In Devriendt, Goossens and Auwera. Berlin: Library of congress Catalonging in Publication. P.149-176.

Dancygier, B. (1998) Conditionals and Predictions: Time, Knowledge, and Causation in Conditional Constructions. Cambridge University Press, Cambridge.

Declerck, R. and Reed, S. (2001) Conditional: A Comprehensive Empirical Analysis. Berlin. New York: Mouton de Gruyter.

Dik, S. (1990) "On the semantics of conditionals", in J. Nuyts, A. M. Bolkenstein\& C. Vet (ed), Layers and levels of representation in language theory, Amsterdam, Benjamins, p. 233-261.

Eastwood, J. (1994) Oxford Guide to English Grammar. Oxford University Press.

Elliott, W. (2006) “Conditional sentences in the New Testament”. Doctoral dissertation, Gordon College. 
Farah, Sh. (2006) "the Acquisition of conditional sentences by Arab Learners of English". Studies in contrastive linguistics proceedings of the international. pp: 253-254.

Fintel, K. (2009) Conditionals. Cambridge University Press.

Fintel, K. (1997) "Bare Plurals, Bare Conditionals, and Only". Journal of Semantics, 14(1), 1-56

Geis, L. and Zwicky, M. (1971) “On invited inferences”. Linguistic inquiry 2, pp.561-566.

Khalil, A. (2010) A Contrastive Grammar of English \& Arabic. Jordan Book Centre.

Katu'za, J. (1986) “A New Look At Conditional Sentences in English”. ELT J, 40(1), 59-60

Kumakiri, T. (2013) Epistemic Modality and Conditional Sentence: On the Presentative Particle of an Arabic Dialect of Tunis (Tunisia).

Liu, H. (2011) "Second Language Acquisition of If-conditionals in English". MA Thesis. National Taiwan Normal University.

Mace, J. (1998) Arabic grammar: a reference guide. Edinburgh University Press.

Norris, R. W. 2003 "How Do We Overcome the Difficulties of Teaching Conditionals?" Bulletin of Fukuoka International University. P: 39-50

Nekoueizadeh, M. and Bahrani, T. (2013) “The Effect of Conversational Shadowing on Teaching and Learning Conditional Sentences". International Journal for Applied Linguistics. 253-267

Polańska, I. (2006) Expressing Condition in English and Polish. Kraków.

Ramírez, T. (2005) “A Grammaticality Judgement Test for the Past Hypothetical / Counterfactual Conditional in English”. RAEL: revistaelectrónica de lingüísticaaplicada, (4), pp.192-230.

O’Grady, W. (1997) "Syntactic development”. Chicago Press.

Ryding, K. (2005) A Reference Grammar of Modern Standard Arabic. Cambridge: Cambridge University Press.

Sultan, J. (2011) "The Translation of English Conditional Clauses into Arabic: A Pedagogical Perspective". Journal of the College of Arts. University of Basrah, (59).

Sweet, H. (1991) A New English Grammar: Logical and Historical. Part I. Oxford.

Mace, J. (1998) Arabic grammar: a reference guide. Edinburgh University Press.

Teschner, V. and. Evans E. (2007) Analysing the Grammar of English. Washington, D.C. Georgetown University Press Traugott, E., Meulen, A., Reilly, J. and Ferguson, C. (1986) On conditionals. Cambridge: Cambridge University.

Wu, M. (2012) “The Probability Approach to English If-conditional Sentences”. English Language Teaching, 5(5), p3738.

Young, R. (1989) “A Classification of Conditional Sentences Based on Speech Act Theory”. Grace Eological Journal. Yule, G. (1998) Explaining English Grammar. Oxford: Oxford University Press, Print.

Zhang, B. (2005) A Study of the Acquisition of English If-conditional Sentences by Chinese Learners. MA Thesis. PLA University. http://www.dissertationtopic.net/doc/899452

\section{Appendices}

Appendix 1

\section{Real and Unreal Conditional Sentences.}

Conditional sentences can be divided into two major categories: real and unreal conditionals (Yule 1998; Cowan 2008; Wu 2012).

\section{Real Conditional Sentences:}

Real conditionals can be realised in both the protasis and the apodosis clauses. Real conditionals indicate true and real, factual conditions under which the event in the consequent clause could be fulfilled. The indicative mood tenses are used in real conditionals. The relationships between protasis and apodosis clauses can be described (habitual and generic conditional sentences), implications can be summed up when a condition in the antecedent clause is fulfilled (inference conditional), and the likelihood of something occurring in the future can be defined (future conditional). These types provide us with a path to understanding the function and meaning of conditionals and the use of modal verbs and tenses with these verbs (Cowan 2008; Wu 2012). In addition, real conditionals consists of four features which can refer to certain kinds of factual and predictive relationship: 
1. Generic Conditional:

A generic conditional refers to facts which appear to be scientific truths. It is used mostly in academic prose (Cowan 2008).

\section{Habitual Conditional:}

A habitual conditional refers to events in the present or past tense and also to the relationships between events which generally occur or are usually true in the situations described. The two clauses can contain verbs in the past or present tense (Yule 1998; Cowan 2008).

\section{Inference Conditional:}

In an inference conditional, the proposition in the consequent clause is expressed by the proposition in the antecedent clause. Inference conditional sentences state that 'if $P$, then $Q$ '. In this structure, $P$ is true but $Q$ may or may not be true. An inference conditional will be in the present or the past. The inference conditional can be formed with more modal verb and tense combinations than habitual or generic conditional sentences (Cowan 2008).

\section{Future Conditional:}

A future conditional refers to a predicted result that will happen in the future. Moreover, in the consequent clause, the event is strongly likely to occur in the future when the condition in the antecedent is fulfilled. The possibility in this case is referred to by the modal verb, which is in the result clause.

There are many specific cases in which future conditionals are used, such as expressing future results that are based on plans or contingencies. In these cases, the antecedent clauses indicate events with verbs in the simple present and the consequent clauses, which use the modal "will", or often, "be going to", refer to future events which rely on the conditions being fulfilled. According to Yule (1998) and Cowan (2008), future conditional sentences can also be used to express instructions, questions and suggestions. This occurs when the antecedent clauses contain the present tense and are followed by these expressions.

There are various degrees of probability for the predictive results that are built into the use of modal verbs in consequent clauses. The following examples show various degrees of probability:

$>$ If he comes now, he should be there at 5 o'clock. (High probability).

$>$ If he comes now, he may be there at 5 o'clock. (Possibility).

$>$ If he comes now, he might be there at 5 o'clock. (Weak possibility).

\section{Unreal Conditional Sentences:}

An unreal conditional is a conditional sentence in which the proposition in the antecedent clause is an imaginative condition, and its imaginative result is in the consequent clause (Cowan 2008). In unreal conditionals, the form refers to conditions that cannot be fulfilled. As has been mentioned before, there are different kinds of supposition, namely suggestions, offers, probabilities and hypotheses. Subjunctive mood forms are used in unreal conditionals and can consist of (1) the past subjunctive, which is used in the antecedent clause to indicate an unreal event in the present or future or (2) the past perfect subjunctive, which is used in the antecedent to indicate an unreal event in the past. Unreal conditionals can be divided into two types, namely hypothetical and counterfactual conditionals. According to Quirk et al (1985) and Celce-Murcia and Larsen-Freeman (1983), hypothetical conditionals refer to unlikely states or events, while counterfactual conditionals refer to impossible states or events.

\section{Hypothetical Conditional:}

A hypothetical conditional expresses suppositions about assumed possible situations in the present and the future. Hypothetical conditionals contrast with future conditionals, which refer to the future outcomes of contingencies or real plans (Cowan 2008). Furthermore, Yule (1998) added that the unlikely events in the result clause are referred to by the antecedent clause. The use of the past tense in the "if-clause" is a sign of the distance of potentiality and modal verbs (might, would, could) are usually used in the result clause. The following example shows the speakers imagining a hypothetical case which could occur in the future:

If he found a purse on the bus, he would give it to the driver.

The hypothetical conditional is typically used to refer to wishes and desires which are improbable; sometimes this can use the verb "were", which is used for all persons ( Wu 2012).

$>$ If I were you, I would go home. 
2. Counterfactual Conditional:

Counterfactual conditionals are conditionals in the past which talk about past situations which were not fulfilled (Cowan 2008). Yule (1998) noted that they express event in their "if-clauses" that are impossible. According to Wu (2012:38), "the event in the result clause is assumed to take place or become true when the situation in the if-clause, which is known to be impossible in the past, is met". The following sentence is an example of this:

If I had bought a car, I would have gone to the sea.

In counterfactual conditionals, the tense is in the past perfect in the antecedent clause and the structure of the main clause is "would have + past participle". The modals "could" and "might" can be used in the main clause instead of the modal "would":

$>$ If he had not seen you, he might have had another appointment.

The following table illustrates the main types of conditional sentence proposed by Yule (1998):

\begin{tabular}{llll}
\hline Real & If-clause verb & Main clause verb & Situations \\
\hline Factual & Present & Present & Generally true \\
\hline Factual & Past & Past & Generally true \\
\hline Factual & Present & Present modal & Likely \\
\hline Unreal & If-clause verb & Main clause verb & Situations \\
& & & \\
\hline Hypothetical & Present & Present & Generally true \\
\hline Counterfactual & Past perfect & Past modal perfect & Impossible
\end{tabular}

\section{Appendix 2}

\section{Questionnaire}

- Group ( )

There are 15 conditional sentences in this test. Some of them are correct and some are not. Read each sentence and then decide whether it is correct or not and write down your answer between the brackets. Where the conditional sentence is incorrect, rewrite it in the lines that follow and explain why the sentence is incorrect.

1. If they go to the restaurant on Sunday, they would see him there. ( )

2. We wouldn't went to the picnic if it didn't stop raining.

3. I would have passed if the exam wasn't difficult. ( ).

4. If I was a millionaire, I would buy a yacht. ( ).

5. If you had a car, you would go to the party. ( ).

6. If Sadi will go home, he will see his aunt. ( ). 
7. If they have worked more, their job would have been developed. (

) .

8. If you had had his contact number, you would have called him any time. ( ).

9. If you had had the book, you would had studied at home. ( ).

10. If you would have studied harder, your English would have gotten better. ( ).

11. She will go to London, if she had a car. ( ).

12. Then they will see you If you come here again. ( ).

13. If I had knew earlier, I would have done it. ( ～）

14. If we need some queries, we should ask the receptionist. (

)

15. You won't be so tired if you took a nap. (

) .

\section{Your name}

\section{All the Best}

